\title{
Micro-Hydro/Solar Hybrid System Framework for Off-Grid Application
}

\author{
Nuramalina Bohari ${ }^{1}$, Wan Azlan Wan Zainal Abidin ${ }^{2}$, Martin Anyi ${ }^{3}$ and Dayang Nur Salmi \\ Dharmiza Awang Salleh ${ }^{4}$ \\ ${ }^{1,2,3,4}$ Department of Electrical and Electronic Engineering, Universiti Malaysia Sarawak, \\ 94300 Kota Samarahan, Malaysia. \\ ${ }^{1}$ Email: nuramalina.b@gmail.com, ${ }^{2}$ Email:wzaazlan@pps.unimas.my, \\ ${ }^{3}$ Email: amartin@feng.unimas.my, ${ }^{4}$ Email: asdnsdharmiza@feng.unimas.my
}

\begin{abstract}
This paper introduces the conceptual system design of micro-hydro/solar hybrid system for Kampung Semulong Ulu, Sri Aman, Sarawak. Currently, Kampung Semulong Ulu is powered by solar and diesel-generator energy systems. The existing solar system generates less than $160 \mathrm{~W}$ for each door of the longhouse. With the completion of micro-hydro system along with the existing solar panel in the village, the community is hoping to get the proper and continuous power generation. Community in Kampung Semulong Ulu is facing difficulties since solar is only available for a limited period and yield electricity within a limited range of load. On the other hand, the running cost of diesel-generator is very expensive and unaffordable. However, even with the existence of power generated by microhydro system, better utilization of the energy produced is still of vital importance due to the fact that the amount of energy generated is limited. Therefore, the conceptual system design of the hydro-solar system integration is presented. The proposed system is to ensure that the energy produced will be well-distributed and at the same time, both systems must be utilized sufficiently to ensure their sustainability. In overall, this paper presents the micro-hydro/solar hybrid system framework for offgrid application toward the community in Kampung Semulong Ulu.
\end{abstract}

Keywords: controller system, micro-hydro, solar, hybrid system, rural area.

\section{Introduction}

Against backdrop of challenging in the modern days with the rapid growth of human population and social-economic development, energy demand has been raising exponentially to cater the energy requirements especially in these current modern societies. In fact, electricity is an ongoing issue and plays a significant role as developed country cannot survive without electricity [1]. The conventional energy is depleting at alarming stage as the human population and activities are progressively developing. Thus, harnessing the renewable energy has attracted special attention among the researchers. Gearing up the renewable energy technology innovation is a great aspiration for many nations as the global requirement for energy generation is growing beyond the limits of current available generation capacity.

The integration between the renewable energy resources systems has grown and of great interest for the developed countries as hybrid renewable energy systems appeared to be the right solution for a clean and well distributed energy productions. Many hybrid systems have been proposed in the past literature studies in order to offer the enhanced power facilities and adequate energy production

Manuscript History:

Received 2 September, 2014, Revised 12 December, 2014, Accepted 23 March, 2015, Published 30 April, 2015

e-ISSN 2289-7771

Copyright $@ 2015$ JASPE

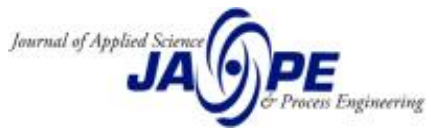


[2] - [6]. A typical hybrid renewable energy is defined as the combination of two or more renewable energy resources such as solar, wind or hydro generations [3]. In hybrid technologies, battery plays a significant role in energy storage purposes. The battery is used to ensure the stability of the system by storing the power produced based on the specified condition either during shortage or excess energy generated by the energy resources [7].

The focus of this paper is to introduce the conceptual system design of micro-hydro/solar hybrid system for Kampung Semulong Ulu, Sarawak. The remainder of the paper is organized as follows: Project area description is presented in section 2. Section 3 focuses on the proposed hybrid system framework while section 4 explains the proposed conceptual design of the hybrid power optimization system toward the community in Kampung Semulong Ulu. Hybrid controller system design is presented in Section 5. Finally, conclusions are drawn in section 6.

\section{Project Area Description}

\subsection{Site Location}

For the purpose of analysis, a rural area located far away from the transmission grid named Kampung Semulong Ulu is selected. Kampung Semulong Ulu is located in the district of Sri Aman, Sarawak. Currently, the village is provided with both solar and diesel-generator generation systems. Figure 1 depicts the location site of hydro power construction in Kampung Semulong Ulu.

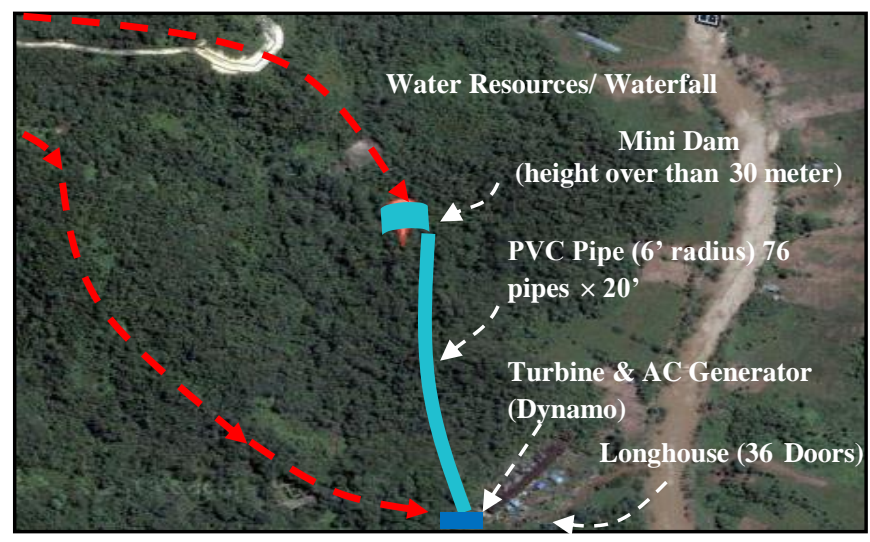

Figure 1. Location Site of On-going Micro-Hydro System in Kampung Semulong Ulu.

The topography of the area as shown in Figure 1 is characterized by consistent and adequate water resources from the waterfalls in the village while also having good solar irradiation. It takes approximately 1 hour and 30 minutes from Pantu, Sri Aman which is the nearest jetty to reach the village using long boat that accommodates 3 to 5 passengers. Since the electricity generated from solar system is limited within the certain period of time, the community still relies on the diesel-generator to cater for the energy demand. This is due to the electricity generated from the solar panel is only sufficient for the very basic electrical appliances such as lamps.

\subsection{Micro-Hydro System}

Realizing the fact that the use of solar energy is limited for a few hours based on battery capacity, the community only has electricity during the night after the batteries are fully charged. Therefore, the construction of micro-hydro power at Kampung Semulong Ulu was aimed to provide a better electricity generation for the community. Table 1 shows the micro-hydro specification in Kampung Semulong Ulu. 
Table 1. Micro-Hydro Specification

\begin{tabular}{|l|l|}
\hline Turbine Type & : Cross Flow Turbine \\
\hline Generator (Watt, W) & $: 5000$ \\
\hline Diameter Penstock (mm) & $: 280$ \\
\hline Size of Weir (meter, m) & $: 200 \times 25 \times 3$ \\
\hline Water Flow Rate $(\mathrm{m} / \mathrm{s})$ & $:>100$ \\
\hline Volume of Water $($ liter/s) & $: 20$ \\
\hline
\end{tabular}

Kampung Semulong Ulu has a great potential for supplying electricity through micro-hydro system development due to a consistent water resources throughout the year with adequate height of waterfalls there. In fact, the water flow rate of the waterfalls reaches up to $100 \mathrm{~m} / \mathrm{s}$ as described in Table 1 which shows a great potential of micro-hydro system development. The water flow rate is conveyed to the hydraulic turbine by the intake channel of PVC pipes as in Figure 1. Meanwhile, Figure 2(a) and Figure 2(b) shows the installed micro-hydro system and power house at Kampung Semulong Ulu.

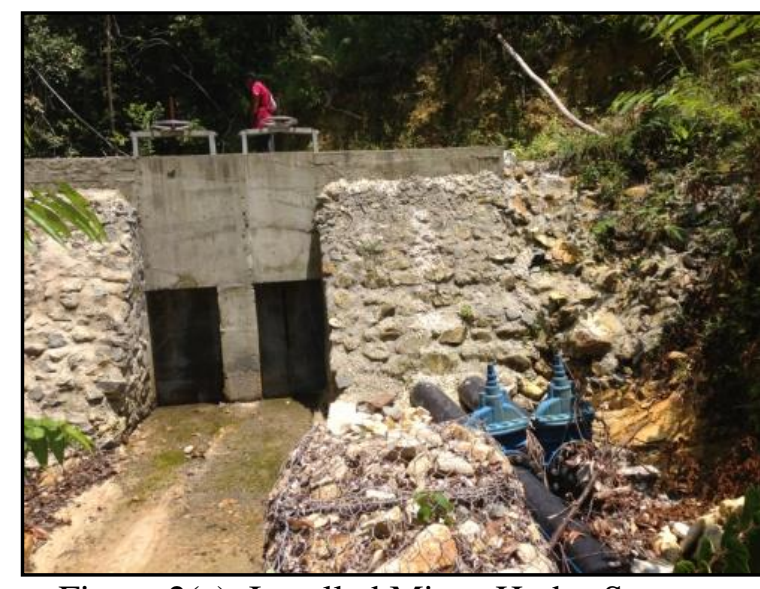

Figure 2(a). Installed Micro-Hydro System.

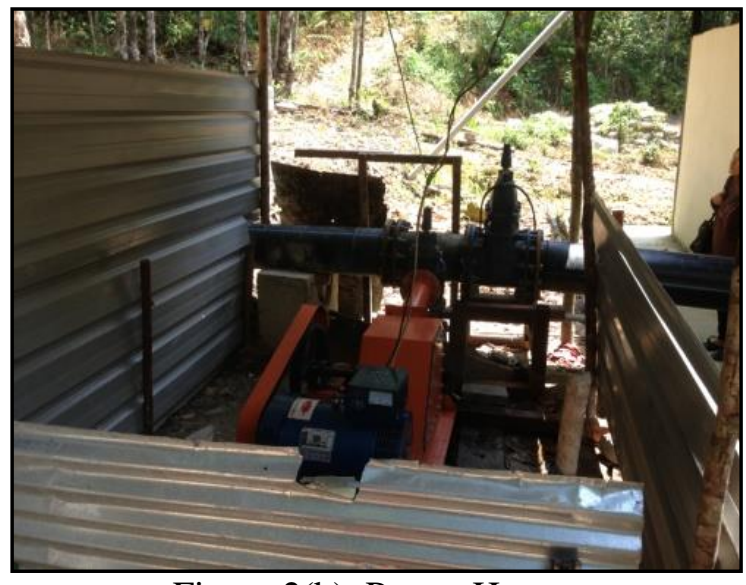

Figure 2(b). Power House.

The current micro-hydro system is not the first system development as the earliest micro-hydro system project was in 2007, but faced failure due to the financial problem and limitation in design system. Then, in 2009, the micro-hydro system with small financial allocations from Universiti Malaysia Sarawak (UNIMAS) also did not achieve the goal of implementation because of lack in technical and knowledge management of the system. Thus, due to the continues failures, currently, Faculty of Engineering of UNIMAS through the Centre of Excellence for Renewable Energy (CoERE) has installed about $5 \mathrm{KW}$ of micro-hydro system at the Iban's longhouse in Kampung Semulong Ulu, Sri Aman by taking all the previous causes of failure into account.

\subsection{Solar System}

As Kampung Semulong Ulu is located in the rural areas, there is still no basic facilities such as grid facility as well as treated water in the area. Although solar energy is supplied by government, but the electricity produced is only able to support few energy saving bulbs. In addition, the use of solar energy is also limited to a few hours and not all the time. Thus, the community still relies on the diesel-generator to cater for the energy demand which is costly. Figure 3 illustrates the existing solar 
system in Kampung Semulong Ulu.

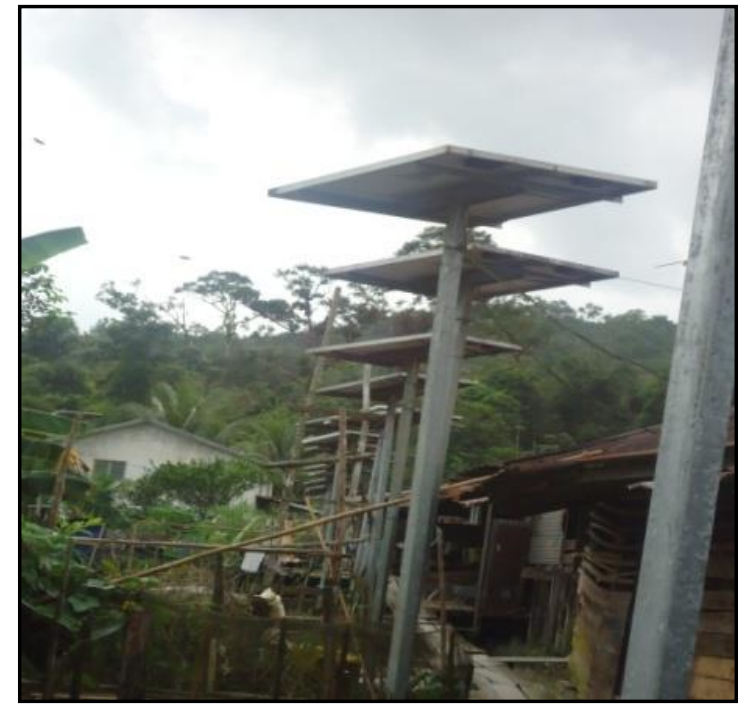

Figure 3. Existing Solar Panel.

The existing solar panel also proves that Kampung Semulong Ulu is having good solar irradiation throughout the year. Solar panels are provided by the government for the longhouse are connected separately for each door. The existing solar system generates less than $160 \mathrm{~W}$ for each door of the longhouse. Table 2 shows the specification of solar panel used in Kampung Semulong Ulu.

Table 2. Solar Panel Specification [8]

\begin{tabular}{|c|l|}
\hline \multicolumn{2}{|c|}{ BP 280F Model } \\
\hline Nominal Peak Power (Pmax) & $: 80.00 \mathrm{~W}$ \\
\hline Peak Power Voltage (Vmp) & $: 17.00 \mathrm{~V}$ \\
\hline Peak Power Current (Imp) & $: 4.70 \mathrm{~A}$ \\
\hline Short Circuit Current (Isc) & $: 5.00 \mathrm{~A}$ \\
\hline Open Circuit Voltage (Voc) & $: 21.80 \mathrm{~V}$ \\
\hline Minimum Power (Pmin) & $: 75.00 \mathrm{~W}$ \\
\hline
\end{tabular}

The usage of energy generated by solar only caters for lighting in the longhouse. Currently, every door has only three $14 \mathrm{~W}$ energy saving bulbs each. The usage of other electrical appliances such as fan and television cannot be used simultaneously as the power generated from the solar panel is not enough and very limited.

\section{Proposed Hybrid System Framework}

\subsection{Hybrid System Framework}

In micro-hydro system performance, the limitation faced due to unstable voltage and frequency regulations in the system. These scenarios occurred due to unbalanced loads exploit by the consumers. For instance, as the voltage regulation of the micro-hydro system are influenced by the speed of generator regulations, the generator tends to slow down when loads are added. Likewise, removing a load would cause the generator to speed up. Hence, in order to maintain the constant voltage and 
frequency with the needs of Malaysia consumer satisfaction, the Electronic Load Controller (ELC) is designed into micro-hydro system. The ELC works as it will automatically adjust the load so that the generator always turns at the right speed. The ELC constantly monitors the voltage in order to compensate the human usage as the excess power is shunted to the ballast load. Thus, the system will constantly generate at 240 volts, $50 \mathrm{~Hz}$ AC to satisfy the needs of Malaysia Standards even though practically the system could reach until 600 volt. In short, the ELC in micro-hydro system will sense the event of overvoltage in the system in order to protect the generator and electrical appliances from damage.

However, other than overvoltage issues, there will be the case when the voltage drops in the system. Generally, the voltage drop occurred by adding progressively higher load which exceed the limit of power produce by the generator. The overload will cause the voltage drop, thus would slow down the generator. Even though micro-hydro system designed the ELC as protection circuit for the system, the ELC only protects the system during the overvoltage but not in the event of voltage drop.

Therefore, particular design to accommodate the limitation of existing micro-hydro and solar system is required. The voltage drop at the system causes the generator to slow down with the increasing number of loads which would cause the generator to run away. The suitable switching action at the load is vital in order to make full use of the power available. Thus, the excess energy produced by the micro-hydro system will be distributed to charge the solar battery so that solar panel will continuously able to be charged during cloudy or rainy days, and even during the night time.

The proposed controller is operated in accordance with the rule-based strategy created in the system. The integration must ensure that the energy produced is well distributed and at the same time, both systems are utilized adequately to ensure their sustainability. Changeover system between the micro-hydro and solar system results in more productive and consistent power generation system. Figure 4 illustrates the detailed proposed hybrid operational scheme for each door of the longhouse.



Figure 4. Proposed Hybrid Operational Scheme System.

In the form of the output presented as in Figure 4, all of the three outputs are controlled in prioritized scheme of which power will be distributed among the switches. And as in this case, the highest priority goes to serve the lightings towards the communities in the longhouse. Therefore, the lightings are still available to utilize even though the voltage drop at minimum state. In fact, the 
changeover system between the micro-hydro system and solar system will allow the lightings to turn on even if when the voltage drop occurred at micro-hydro system. The excess energy produced by the micro-hydro system will be distributed to the AC charger so that the battery of the solar panel will continuously able to be charged during cloudy or rainy days, and even during the night time. The rectifier is required to convert the $\mathrm{AC}$ to $\mathrm{DC}$ current of the $\mathrm{AC}$ charger before it store in the batteries.

\section{Proposed Conceptual Design of Hybrid Power Optimization System}

The development of existing hybrid control strategies is gaining a high momentum, especially for a grid-off application. Various mathematical modelings as well as different types of designs and simulation results of hybrid renewable energy system have been published. Recently, most of the systems are controlled by a mean of rule-based strategy acting on common DC bus and thus influenced the whole system performance [9]. On the other hand, the combination controlled strategy patterned at both AC/DC buses has also been introduced. The concept of hybrid AC/DC system is hence emerging to combine the benefits of both types, while reducing losses by avoiding multiple power-electronic conversion stages and increase the system reliability [10].

Likewise, a past literature study in relation to this hybrid proposed system has been carried out in Northern India which is projected to apply for domestic use only [11]. However, the literature study defines the hybrid performance as both of generating energy of solar and wind will be stored at the charge controller and directly transfer to the battery before it transmits the power to the consumers. Hence, the controller strategy is different as this proposed hybrid controller is regulate the AC power of both micro-hydro and solar system and thus will drive the switching action at the load, primarily for the lighting, sockets and AC charger to charge for the solar battery as the proposed hybrid system particularly applied to rural areas instead for domestic purposes.

The existing of micro-hydro and solar panel at the village derived the hybrid controller strategy is patterned at the AC transmission line. This is due to the fact that the disoriented performance between micro-hydro and solar system could happen as originally both system is implemented to operate separately. In fact, the aim of this system is to exploit both of the system sufficiently while also to formulate the suitable algorithm for micro-hydro and solar system.

Moreover, realizing the fact that the regulations of amplitude of frequency and voltages are important for the whole power systems also become the main reason of the controller system was designed at the $\mathrm{AC}$ bus power system [11] - [12]. Consequently, in electric power, the power generated is usually controlled by the frequency and the voltage of the system [13] - [15]. Thus, in this paper, the AC voltage from the micro-hydro system will perform as the input parameter. The microhydro system will perform as the main power sources as micro-hydro system is more dependable and generate more stable and higher power compares to solar panel. Voltage regulation of the load controllers will govern the speed of the turbine generator of the system. Therefore, it is certain that micro-hydro system generates variable values of input voltages. Meanwhile, the three-switch system at the longhouse will present as the output parameters. Basically, the switches are for lightings, sockets, and solar charger system for each door in the longhouse. Table 3 shows the conditions for proposed hybrid controller system.

Table 3. Conditions for Proposed Hybrid Controller System

\begin{tabular}{|l|c|c|}
\hline \multicolumn{1}{|c|}{ Conditions } & Operating Voltage, $\mathrm{V}$ & Output $(\mathrm{SW} 1, \mathrm{SW} 2, \mathrm{SW} 3)$ \\
\hline 1 (Maximum) & $240<\mathrm{V}<220$ & SW1, SW2, SW3 \\
\hline 2 (Medium) & $219<\mathrm{V}<201$ & SW1, SW2 \\
\hline 3 (Minimum) & $200<\mathrm{V}<180$ & SW1 \\
\hline
\end{tabular}

Each condition as in Table 3 is specified by a different range of operating voltages. The three switches will perform in three different scenarios based on the specified condition created at the input. 
The minimum voltage used is 180 volts, and reaches up to only 240 volts even though practically, the micro-hydro system could reach until 600 volts.

Based on Table 3, if the input voltage is between 180 and 200 volts, the lighting switch (SW1) will be turned on. When the input voltage is from 201 to 219 volts, both of the lightings (SW1) and available sockets (SW2) for fan and television will be activated. All of the three-switch are switched on when the voltage range is from 220 to 240 volts. However the input voltage are not finalized yet after hardware implementation and testing part are accomplished.

Particularly, the proposed hybrid system is aiming to improve the previous electricity distribution for each door in the longhouse. The input voltage sense from micro-hydro transmission line, and thus will transmit to the microcontroller. The algorithm in microcontroller defines the input voltage and selects the various switching operations. Figure 5 illustrates the hybrid controller strategy flow chart for the project.



Figure 5. Hybrid Controller Strategy Flow Chart.

The hybrid controller strategy as shown in Figure 3 is implemented in assembly language programming. However, the input for operating voltage as in Table 3 is not finalized yet as the project is still at the preliminary stage of implementation. The value for each voltage in each condition will be finalized once the hardware development and testing part is done. 
In the project, the hybrid system is defined as the excess energy from a micro-hydro system will charge an AC charger, so that the solar batteries are still charged even in rainy days and during night. As a result, the combination of micro-hydro and solar system can be more productive and consistent thus will provide continuous power generation towards rural communities. Table 4 shows the comparison of the estimated load demand for each door of the longhouse.

Table 4. Comparison of the Estimated Load Demand for Each Door of the Longhouse

\begin{tabular}{|l|c|c|c|c|c|c|}
\hline & \multicolumn{3}{|c|}{$\begin{array}{c}\text { Before } \\
\text { (Solar Only) }\end{array}$} & \multicolumn{2}{c|}{$\begin{array}{c}\text { After } \\
\text { (Solar and Hydro System) }\end{array}$} \\
\hline Equipment & $\begin{array}{c}\text { Power } \\
\text { Per Unit } \\
\text { (W) }\end{array}$ & Quantity & $\begin{array}{c}\text { Total } \\
\text { Power } \\
(\mathbf{W})\end{array}$ & $\begin{array}{c}\text { Power } \\
\text { Per Unit } \\
(\mathbf{W})\end{array}$ & Quantity & $\begin{array}{c}\text { Total } \\
\text { Power (W) }\end{array}$ \\
\hline Light Bulb & 14 & 3 & 42 & 14 & 6 & 84 \\
\hline Television & 60 & 1 & 60 & 60 & 1 & 64 \\
\hline Fan & 95 & 1 & 95 & 95 & 1 & 95 \\
\hline
\end{tabular}

As shown in Table 4, currently, there are three existing power saving bulbs for each door, which are powered by the solar energy system and these existing bulbs will remain. The proposed system design will add another three bulbs with the same power capacity, but powered by micro-hydro system design. Therefore, there will be six bulbs for each door which are powered by solar and micro-hydro system separately. However, the solar battery can also be charged by the energy excess from hydro power system even during night time. The utilization of television and fan can be powered simultaneously in the longer period of time once the construction of hybrid system is completed.

Although the comparison of the estimated load demand for each door of the longhouse as in Table 4 are not obviously shows the different of total power generated by solar and micro-hydro/solar hybrid system, practically, through the hybrid system, their overall living standard could be improved as the utilization of rice mills and other electrical appliances are available without the use of diesel-generator. In fact, the community in Kampung Semulong Ulu relies on the agricultural and fisheries work as their livelihood. The communities are utilizing the diesel-generator for the rice mill which is expensive and unaffordable for everyone. Thus, once the hybrid system development is completed, the communities can enhance their source of income since previously their economic development and social growth are stunted due to the limitation in power supply.

\section{Hybrid Controller System Design}

As the project utilized assembly language programming for the system design, the 8051 microcontroller model is used for hardware development part. The 8051 microcontroller model used is AT89S8253. This project utilizes 8051 is because it can be programmed easily with simple assembly language programming. On the other hand, since 8051 microcontroller does not have the internal analog to digital converter, the ADC0804 is used to convert the analog voltage input to digital forms before the data is transmitted to the microcontroller. Figure 6 illustrates the hybrid controller circuit design for the project. 


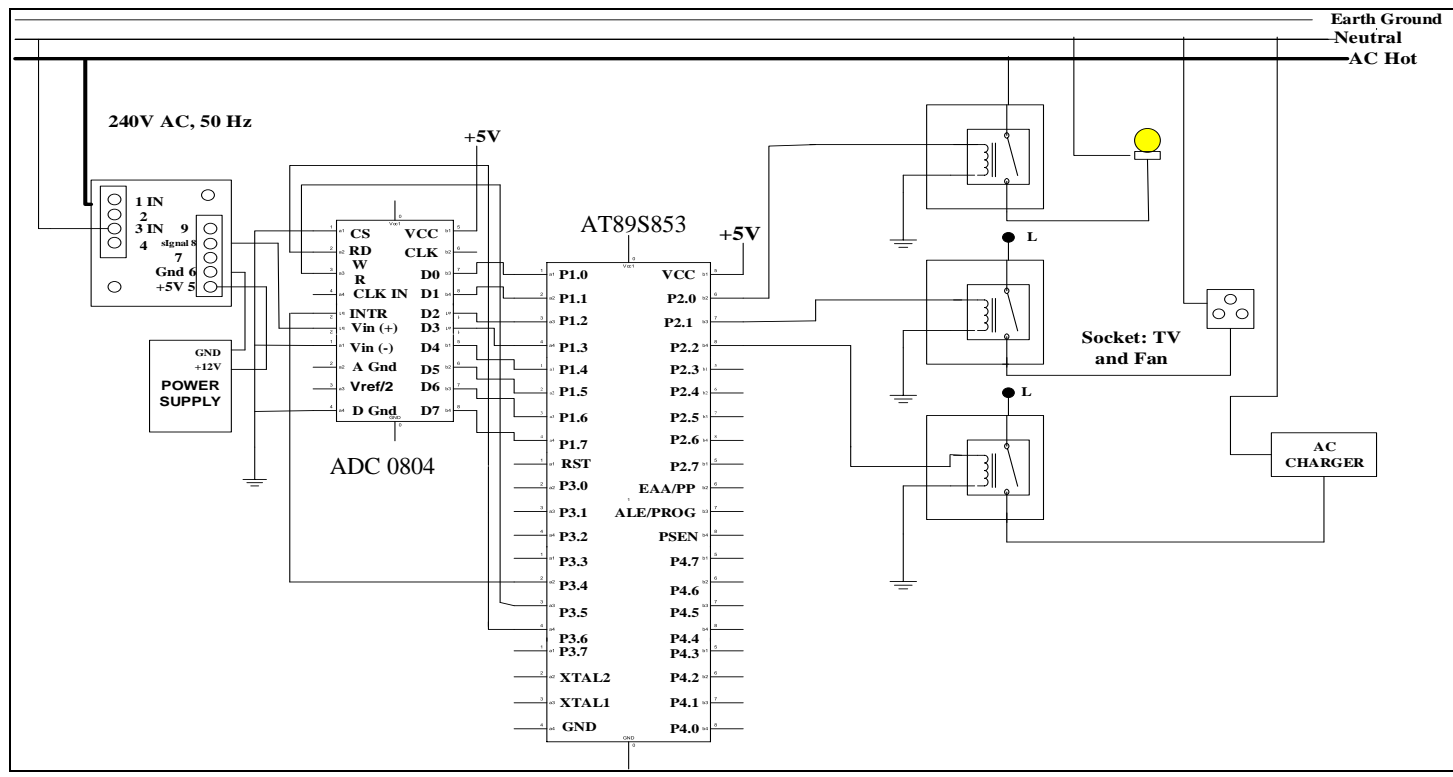

Figure 6. Hybrid Controller Circuit Design.

The microcontroller senses for the output from the ADC 0804 and sends corresponding signal to P0 pins which has been connected to the relay controller circuit as shown in Figure 6. The switching action at the relay will turn off the specified switch based on the created algorithm as the voltage of the micro-hydro system are influenced by the speed generator regulations which tends to slow down when loads are added. In the project, the LED illustrates which output is applicable based on the available voltage senses at micro-hydro system. Figure 7 depicts the preliminary results by the LED.



Figure 7 (a). Result for Condition 1.



Figure 7 (b). Result for Condition 2.



Figure 7 (c). Result for Condition 3. 
The results as in Figure 7 shows that the LED is turned on properly according to the operational voltage as patterned in Table 3 and Figure 5. The P0 port performs as the switching action at the output. The P0.0 represents lighting switching, while P0.1 acts as sockets switching and P0.2 is for AC charger switching. All P0.0, P0.1 and P0.2 are switched on as in Figure 7 (a) if the voltage input meets condition 1 as all of the LEDs are glowing. As the voltage drop to condition 2, the AC charger will be automatically switched off as in Figure 7 (b). Figure 7 (c) illustrates when the voltage meets condition 3 as it will only switch on the lighting. In the proposed system, the software implementation is completed by using 8051 Assembly language programming, while the hardware development as in Figure 6 will be presented in prototype only.

\section{Conclusion}

The herein presented work proposed the general layout of the hybrid controller system design which will be applied in Kampung Semulong Ulu, Sarawak. Once the controller system is installed successfully, it will grant the continuity of power supply in the village within the satisfied load demand for each door in the longhouse. The children will be able to study at night with longer lighting time while they also could save the cost on getting fuels like kerosene. As a result, their overall living standard will be improved once the combined system of micro-hydro and solar system developments are sustained.

In the proposed controller system, the hybrid application is performed when the excess energy generated by a micro - hydro system is utilized to charge the AC charger as well. Therefore, the solar charger can always be charged as long as there is an excess energy produced from micro-hydro system. Thus, solar and micro-hydro system can be used simultaneously during cloudy or rainy days without time constraint. The lighting and various electrical appliances such as fan and television also can be used at the same time with longer period of time. In fact, the hybrid controller system is aimed to improve the previous electricity distribution for each door in the longhouse. Therefore, the system must be well managed and maintained properly. For that reason, CoERE established Knowledge Transfer Programme (KTP) towards the rural community in Kampung Semulong Ulu. The microhydro workshop aimed to produce 'Local Champion' which will be the source of reference for the other villagers. The workshop is aimed to expose the selected participants on the theoretical and technical knowledge of micro-hydro management in order to ensure the sustainability of the system. With the involvement from the local community, UNIMAS is confident that the system will last as the system will be well managed and maintained.

\section{Acknowledgement}

The authors would like to thank the Ministry of Higher Education Malaysia for funding this research work under the Knowledge Transfer Programme (KTP) Grant (L18403/F02/00/KTP) and Universiti Malaysia Sarawak for the research facilities provided. 


\section{References}

[1] Junhui Zhao, Korey Graves, Caisheng Wang, Gene Liao, and Chih-Ping (2012). A Hybrid Electric/Hydro Storage Solution for Standalone Photovoltaic Applications in Remote Areas, IEEE Power and Energy Society General Meeting, pp. 1-6.

[2] Nahid-ur-RahmanChowdhury, Syed Enam Reza, Tofaeel Ahamednito, Abd-Al-Fattah-Ibne Mahabub (2012). Present Scenario of Renewable Energy in Bangladesh and a Proposed Hybrid System to Minimize Power Crisis in Remote Areas, International Journal of Renewable Energy Research, Vol 2, Number 2, p.p 281-288.

[3] Dorin Bica, Cristian Dragos, Dumitru Adrian Gligor, Adrian-Vasile Duka (2009). Isolated Hybrid SolarWind-Hydro Renewable Energy Systems, T.J Hammons(Ed), In Tech.

[4] TenMahdi Sadiqi, Anil Pahwa, and Ruth Douglas Miller (2012). Basic Design and Cost Optimization of a Hybrid Power System for Rural Communities in Afghanistan, North American Power Symposium (NAPS) , pp 1-6.

[5] Dada Delimustafic, Jasmina Islamicbegovic, Abdullah Aksamovic and Semsudin Masic (2011). Model of a Hybrid Renewable Energy System: Control, Supervision and Energy Distribution, IEEE International Symposium on Industrial_Electronics (ISIE) 2011, p.p 1081-1086.

[6] Phatiphat Thounthong, Arkhom Luksanasakul, Poolsak Koseeyaporn, and Bernard Davat (2013). Intelligent Model-Based Control of a Standalone Photovoltaic/Fuel Cell Power Plant with upercapacitor Energy Storage, IEEE Transactions on Sustainable Energy, Vol. 4, No. 1.

[7] Jae Woong Shim, Youngho Cho, Seog-Joo Kim, Sang Won Min, and Kyeon Hur (2013). Synergistic Control of SMES and Battery Energy Storage for Enabling Dispatchability of Renewable Energy Sources, IEEE Transactions on Applied Superconductivity, Vol. 23, No. 3.

[8] BP Solar Technical Specification Catalogue BP280F. Available: http://www.oksolar.com.

[9] Giacomo Bruni, Stefano Cordiner, Matteo Galeotti, Vincenzo Mulone, Matteo Nobile, Vittorio Rocco (2014). Control Strategy Influence on the Efficiency of a Hybrid Photovoltaic-Battery-Fuel Cell System Distributed Generation System for Domestic Applications, 68th Conference of the Italian Thermal Machines Engineering Association ATI2013. pp. 237 - 246.

[10] Amr Ahmed A. Radwan, and Yasser Abdel-Rady I. Mohamed (2014). Networked Control and Power Management of AC/DC Hybrid Microgrids, IEEE Systems Journal. pp. 1-12.

[11] Vivex Dixit, J.S. Bhatia (2013). Analysis and Design of a Domestic Solar-Wind Hybrid Energy System for Low Wind Speeds, International Journal of Computer Applications, Vol. 72, No. 22. pp. 40-44.

[12] O. Wasynczuk, L. J. Rashkin, S. D. Pekarek, R. R. Swanson, B. P. Loop, N. Wu, S. F. Glover, J. C. Neely (2012). Voltage and Frequency Regulation Strategies in Isolated AC Micro-Grids, Proceedings of the 2012 IEEE International Conference on Cyber Technology in Automation, Control and Intelligent Systems, pp. 5-10.

[13] Daniel A, Guide to Hydropower -An Introduction to Hydropower Concepts and Planning, Available: http://www .canyonhydro .com.

[14] Shoan Mbabazi, Jon Leary (2010). Analysis and Design of Electronic Load Controller for Micro-Hydro System in Developing World, Mini Project Report The University of Sheffield, pp 1-14.

[15] Chen Wu, Hamed Mohsenian-Rad, Jianwei Huang, and Juri Jatskevich (2012). PEV-Based Combined Frequency and Voltage Regulation for Smart Grid, Proceedings of the 2012 IEEE PES Innovative Smart Grid Technologies, pp 1-6. 


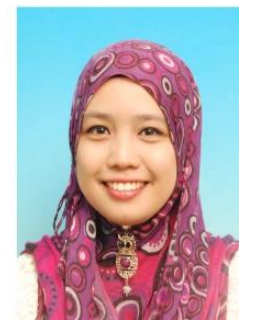

\section{Nuramalina Binti Bohari}

Nuramalina Binti Bohari is a postgraduate student, attached to the Department of Electrical and Eletronic, Faculty of Engineering, Universiti Malaysia Sarawak (UNIMAS).



\section{Assoc. Prof. Wan Azlan Wan Zainal Abidin}

Assoc. Prof. Wan Azlan Wan Zainal Abidin is a lecturer, attached to the Department of Electrical and Eletronic, Faculty of Engineering, Universiti Malaysia Sarawak (UNIMAS). He received his Associate Professor in 2014. His field of interest is computer science and communication.

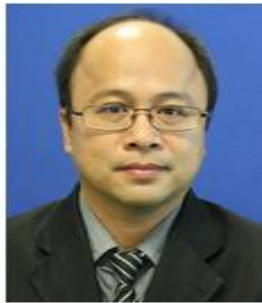

\section{Dr. Martin Anyi}

Dr. Martin Anyi is a senior lecturer, attached to the Department of Electrical and Eletronic Energy, Faculty of Engineering, Universiti Malaysia Sarawak (UNIMAS). He received his $\mathrm{PhD}$ in 2014. His field of interest is computer science and communication.



\section{Dayang Nur Salmi Dharmiza Awang Salleh}

Dayang Nur Salmi Dharmiza Awang Salleh is a lecturer, attached to the Department of Electrical and Eletronic, Faculty of Engineering, Universiti Malaysia Sarawak (UNIMAS). He received his master in 2013. His field of interest is electronics and applied physics. 